\title{
Measurement of the Effective Dose Radiation at Radiology Departments of Some Hospitals in Duhok Governorate
}

\author{
Dindar S. Bari, Pshtiwan M. Amin, Nawzad A. Abdulkareem \\ Department of Physics, Faculty of Science, University of Zakho, Zakho, Iraq \\ Email: dindar.dosky@yahoo.com
}

Received 4 March 2015; accepted 9 April 2015; published 10 April 2015

Copyright (C) 2015 by authors and Scientific Research Publishing Inc. This work is licensed under the Creative Commons Attribution International License (CC BY). http://creativecommons.org/licenses/by/4.0/

\section{(c) (i) Open Access}

\section{Abstract}

During operating of the X-ray machines, if the protection of X-ray rooms is insufficient, not only the patient but also clinical staffs as well as public are exposed to high $\mathrm{X}$-ray dosage and they are affected from X-ray related to the dose level. In the present survey, by testing the radiological leakage and scatter from $X$-rays machines in radiology departments of 7 randomly selected hospitals in Duhok governorate, the effects dose of X-ray to the both control panel area and the patients waiting or visiting area who are located near the radiography room, were measured. The dose was recorded for a range of peak kilovoltage $(\mathrm{kVp})$ and $\mathrm{mAs}$ values to find efficiency of shielding materials (barriers) of radiography rooms for different $\mathrm{X}$-rays level. The measurements were performed at one meter above the ground surface which was the same height of $X$-rays tube by using Gamma Scout dosimeter. From the measurement results, it was seen that the most hospitals barriers (doors and walls) were not appropriate to the standards except 2 hospitals. The maximum effective doses were measured in uncontrolled area of Khazer hospital which was 82.48 $\pm 0.73 \mathrm{mSv} \cdot \mathrm{yr}^{-1}$ that was much more than the reference dose limits and in controlled area of Haval Banda Zaroka hospital which was $12.98 \pm 0.16 \mathrm{mSv}^{\cdot} \mathrm{yr}^{-1}$. In result, the knowledge about the radiation dose affecting the radiologists and public in the selected hospitals was obtained, and by informing the radiologists and the hospitals managements, the necessary regulations would be planned.

\section{Keywords}

Radiation Dose, Leakage Radiation, Radiation Protection, Diagnostic X-Ray, X-Ray Room, Duhok Hospitals, Controlled and Uncontrolled Areas 


\section{Introduction}

In recent decades and after discovery of X-ray by Wilhelm Roentgen in 1895, there is a linear development in medical imaging and increase in number of X-ray machines, especially, those used for diagnosis. It is used as the source of dependence for crucial medical decisions. The benefits are immense and certainly exceed the risks. However, although diagnostic X-ray provides great benefits that their use involves some risks of developing human carcinogen is generally accepted [1]. It cannot be ignored that the diagnostic X-ray procedures contribute maximum population dose as compared to other man made radiation sources. Therefore, $\mathrm{X}$-ray beam must be constricted to outside (both controlled and uncontrolled area) of X-ray departments by protecting them with high shielding materials such as lead. Patients, clinical staffs and public must be carefully protected from un-useful beam of X-ray. Patients are protected by installing good and carefully calibrated X-ray machines, while clinical staffs and public are protected by building high protected X-ray rooms.

Photons penetrating through of X-ray room may be divided into two groups; photons that are generated from primary beam scattering that is used for diagnosis and photons that penetrate the X-ray tube (leakage) [2]. Both groups contribute the dose at the control and uncontrolled areas which depends on the thickness, elemental composition, and density of the concrete walls as well door and window of the room.

Based on International Commission on Radiological Protection [3]-[5] and International Atomic Energy Agency [6] recommendations for the annual limit of effective dose to members of the general public that are in uncontrolled areas such as patients, visitors to the facility, and employees who do not work routinely with radiation sources, shielding designs should limit exposure to an effective dose that does not exceed $1 \mathrm{mSv}$ per single year [7]. Radiologists are occupationally exposed to low level of ionizing radiation during normal working. However, the dose level should not exceed $1 \mathrm{mSv}$ in a single year with the maximum possible limit of $20 \mathrm{mSv}$ per year [6] [8]. As the dose level exceed limit the probability of occurring cytogenetic abnormalities and fatal cancer risk for the clinical staffs performing diagnostic procedures would increase [9]. The dose received by the clinical staff changes from machine to machine, number of patients and working hours per day and safety precautions followed. The best way to ensure that personnel are following effect safety rules is with personnel monitor and this is recommended by all radiation protection agencies. The dosimeter must be fixed so that it measures good indication of the radiation dose uniformly received on the body.

To prevent scattering radiation, when designing new facilities the design should be to a standard that will keep the doses to clinical staffs and members of the public as low as reasonably achievable (the ALARA principle) taking social and economic factors into account. This means that the facility should be designed to ensure that the radiation exposure of clinical staffs and members of the public are much lower than those of the legal dose limits [10]. It is advisable to check periodically the X-ray installations for proper filtration, $\mathrm{kVp}$ calibration, mAs linearity, leakage radiation etc. [8].

Scatter measurements and predictions of staff doses are performed in the past in sorts of studies [2] [10]-[13]; however, all generally relate to specific equipment and examinations. It is hard to interpret these results with any degree of precision for other units, even for same make units, due to variations in output and examination techniques. Therefore it is important to measure scatter radiation on each unit.

In some hospitals of Duhok governorate, $\mathrm{X}$-ray rooms are not well designed as recommended by radiation protection agencies to restrict radiation doses. When X-ray machines are operated, protection is insufficient as a result radiation is reached to the staff area as well as public. Another problem is that unlike many hospitals in developed countries almost radiologists in those hospitals do not use personal dosimeters to monitor the occupational doses received from X-ray procedures. By these ways the radiation protection principles are neglected.

To study the existing conditions of various diagnostic X-ray facilities and radiation dose received by clinical staff and public during various radiological procedures, a survey has been undertaken for some selected hospitals in Duhok governorate.

\section{Materials and Method}

This survey has been carried out by the measurement of the effective dose due to leaked and scattered radiation from diagnostic X-ray rooms in 7 randomly selected public hospitals in Duhok governorate, Kurdistan region, Iraq. Dose was monitored by a portable dosimeter called Gamma scout. The device is equipped with an endwindow Geiger-Muller counter cylindrical tube enabling to detect different kinds of ionizing radiation such as gamma and X-rays. Therefore, it was suitable for the current survey to detect and measure effective dose from 
X-ray. The dosimeter was used to measures the effective dose at the control area, exact position of working radiologists and uncontrolled area such patient waiting area or corridors near main door of diagnostic X-ray units as shown in Figure 1.

Measurements were performed during the daytime, normal working hours of the selected hospitals which were five hours per day from 8 AM to 1 PM morning shift and 6 days per week. Measurements were carried out at one meter above the ground surface by fixing the dosimeter on a stand of one meter height which was approximately parallel to the X-ray tube with the same height. Before the machines were switched on, the background radiation was measured in all selected hospitals. Subsequently after the exposure to the radiation, the fall out radiation was measured in control panel and patient waiting area. Machines were operated for a range of energies (60, 81 and $105 \mathrm{KeV}$ ) and X-ray intensities (1.4, 28 and $45 \mathrm{mAs}$ ) which represents the exposures for diagnostic imaging of body parts such as hands and legs, nasal sinus and vertebrae respectively. For each exposure three measurements were recorded to reduce the statistical error and calculating standard deviation. Above

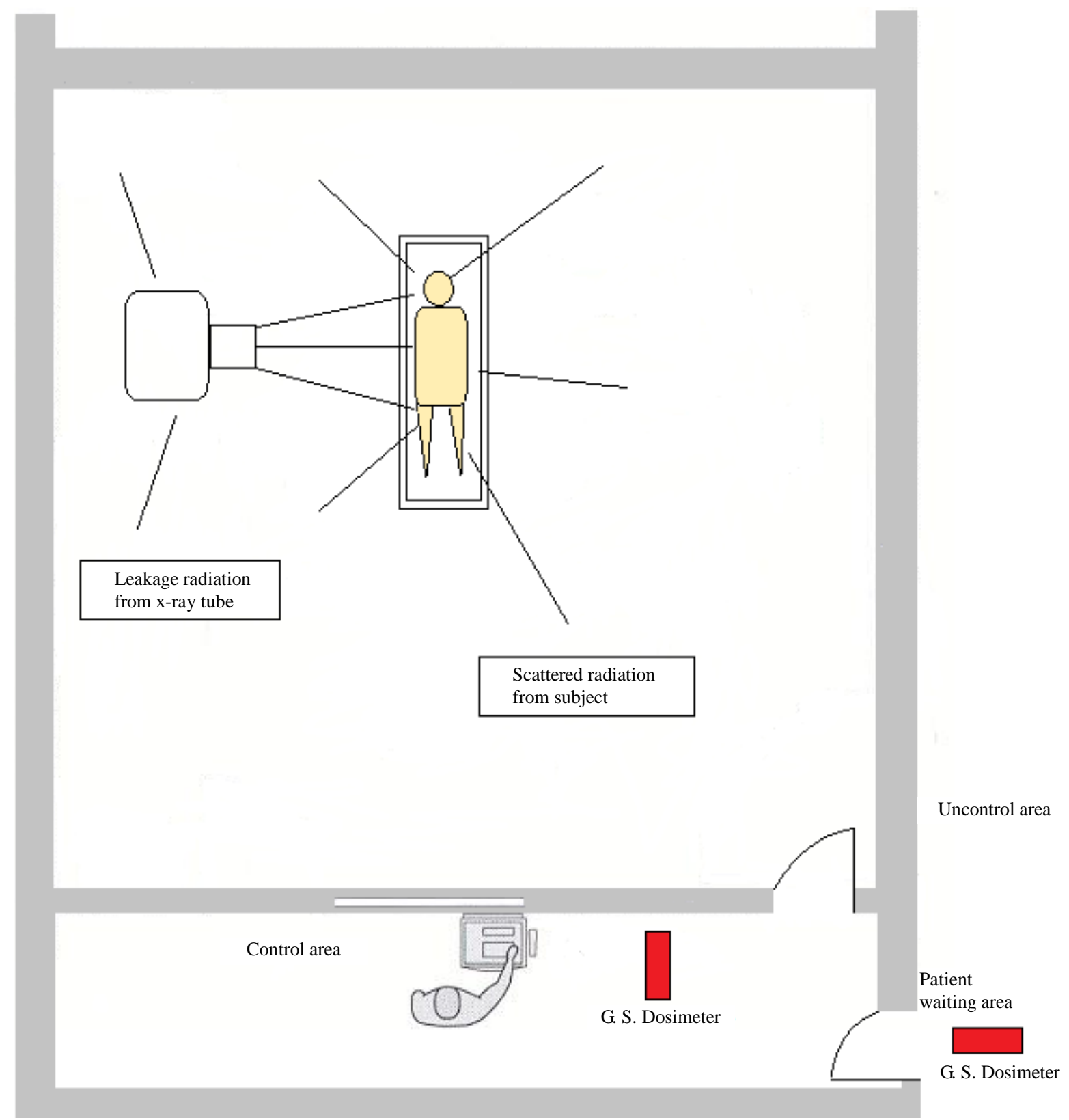

Figure 1. Diagram of the X-ray room at Bahdinan hospital. 
exposure ranges and types of imaging were selected because are most popularly applied in the selected hospitals. Data collected by the utilized dosimeter were measured in unit $\mu \mathrm{Sv} / \mathrm{hr}$ and are converted into mSv/yr.

\section{Results and Discussion}

The effective dose rates were measured in different selected hospitals in Duhok governorate using Gamma scout dosimeter. The results of effective dose rate $\left(\mathrm{mSv} \cdot \mathrm{yr}^{-1}\right)$ measurements for controlled and uncontrolled area are shown in Table 1. Doses are changed from one hospital to another depending on the building design and structure of X-ray rooms. Mean is the average of three measurements for each $\mathrm{kVp}$ and $\mathrm{mAs}$ values. All measurements are with background radiation which was approximately equal at all hospitals. Background radiation was $0.14 \mu \mathrm{Sv} \cdot \mathrm{h}^{-1}$ and is normal range of the dose in Duhok governorate.

It can be shown that as the X-rays parameters $(\mathrm{kVp} \& \mathrm{mAs})$ were increased more $\mathrm{X}$-ray is penetrated through $\mathrm{X}$-rays rooms and detected by the dosimeter at the both controlled and uncontrolled areas. Also it can be seen that in Table 1 the recorded dose values in both Bahdinan and Zakho are in normal ranges and is from background radiation. However, in all other hospitals dose values are more than normal ranges especially in uncontrolled area (public area) in compare to the reference limit $1 \mathrm{mSv}$ per year for public exposure [3]-[6]. This means that photons of X-rays are penetrated through diagnostic rooms of these hospitals due to inefficiency of walls or doors of the rooms. Giri et al. (2007) measured radiation dose in public area at some hospitals in Kathamandu City, it was found that the dose range was between 2.63 and $5.13 \mathrm{mSv} / \mathrm{yr}$ which exceed reference limit for public exposure.

Table 1. The measured dose in controlled and uncontrolled areas in selected hospitals.

\begin{tabular}{|c|c|c|c|c|}
\hline \multirow{2}{*}{\multicolumn{3}{|c|}{ Hospitals $\mathrm{kV}_{\mathrm{p}} \mathrm{mAs}$}} & \multicolumn{2}{|c|}{ Mean \pm SD $(m S v / y r)$} \\
\hline & & & \multirow{2}{*}{$\begin{array}{c}\text { Controlled A. } \\
0.23 \pm 0.01\end{array}$} & \multirow{2}{*}{$\begin{array}{c}\text { Uncontrolled A. } \\
0.21 \pm 0.01\end{array}$} \\
\hline & 60 & 1.4 & & \\
\hline \multirow[t]{3}{*}{ Bahdinan } & 81 & 28 & $0.24 \pm 0.02$ & $0.21 \pm 0.02$ \\
\hline & 105 & 45 & $0.25 \pm 0.01$ & $0.22 \pm 0.02$ \\
\hline & 60 & 1.4 & $0.20 \pm 0.01$ & $0.20 \pm 0.01$ \\
\hline \multirow[t]{3}{*}{ Zakho } & 81 & 28 & $0.22 \pm 0.03$ & $0.20 \pm 0.01$ \\
\hline & 105 & 45 & $0.23 \pm 0.02$ & $0.20 \pm 0.02$ \\
\hline & 60 & 1.4 & $0.21 \pm 0.01$ & $0.22 \pm 0.03$ \\
\hline \multirow[t]{3}{*}{ Golan/Semel } & $81^{*}$ & $28^{*}$ & ------------- & ------------ \\
\hline & 105 & 45 & $1.85 \pm 0.03$ & $0.56 \pm 0.07$ \\
\hline & 60 & 1.4 & $0.26 \pm 0.01$ & $0.25 \pm 0.01$ \\
\hline \multirow[t]{3}{*}{ Haval Banda Zaroka } & 81 & 28 & $2.28 \pm 0.11$ & $1.80 \pm 0.08$ \\
\hline & 105 & 45 & $12.98 \pm 0.16$ & $12.93 \pm 0.25$ \\
\hline & 60 & 1.4 & $0.22 \pm 0.01$ & $0.21 \pm 0.03$ \\
\hline \multirow[t]{3}{*}{ Golan/Akre } & 81 & 28 & $0.40 \pm 0.07$ & $0.27 \pm 0.03$ \\
\hline & 105 & 45 & $3.21 \pm 0.81$ & $0.31 \pm 0.01$ \\
\hline & 60 & 1.4 & $0.28 \pm 0.04$ & $0.28 \pm 0.02$ \\
\hline \multirow[t]{3}{*}{ Khazer } & 81 & 28 & $0.84 \pm 0.02$ & $7.31 \pm 0.12$ \\
\hline & 105 & 45 & $4.52 \pm 0.61$ & $82.48 \pm 0.73$ \\
\hline & 60 & 1.4 & $0.21 \pm 0.02$ & $0.27 \pm 0.02$ \\
\hline \multirow[t]{2}{*}{ Shekhan } & 81 & 28 & $1.48 \pm 0.23$ & $0.36 \pm 0.03$ \\
\hline & 105 & 45 & $8.96 \pm 0.40$ & $3.16 \pm 0.18$ \\
\hline
\end{tabular}

$81^{*}$ and $28^{*} / \mathrm{X}$-ray tube did not work for this $\mathrm{kVp}$ and $\mathrm{mAs}$ values at Golan/Semel hospital due to a problem in control panel. 
A comparison can be made between all hospitals according to the recorded values of the dose at both areas controlled and uncontrolled. Table 2 presents radiation measurement at control area; measured values are rearranged from maximum to minimum values. It can be noted that the highest values $\left(2.28,12.98 \mathrm{mSv} \cdot \mathrm{yr}^{-1}\right)$ are measured in Haval Banda Zaroka hospital for X-ray parameters (81, $105 \mathrm{kVp}$ and 28, $45 \mathrm{mAs}$ ). The measured values are below reference limits $\left(20 \mathrm{mSv} \cdot \mathrm{yr}^{-1}\right)$ of the NCRP organization for radiation workers; however, these values are not normal and can be reduced by fixing the room and installing shielding materials. Also dose in Shekhan hospital somewhat is high $\left(1.48,8.96 \mathrm{mSv} \cdot \mathrm{yr}^{-1}\right)$ and are above normal ranges. Dose in Khazer and Golan hospitals (Akre and Semel) also are more than normal ranges. This suggests the risks associated to employees and clinical staff involved in these facilities. Therefore, immediate radiation protection measures to be initiated to the employees (radiologists, technicians and attendants).

The maximum to minimum dose values in uncontrolled area are shown in Table 3. Unexpected dose values (7.31, $82.48 \mathrm{mSv} \cdot \mathrm{yr}^{-1}$ ) for X-ray parameters $(81,105 \mathrm{kVp}$ and $28,45 \mathrm{mAs})$ are recorded in Khazer hospital. These values are much more than the prescribed level of $1 \mathrm{mSv} \cdot \mathrm{yr}^{-1}$ for public exposure that is suggested by all radiation protection organizations [3]-[6]. Also mean amount of radiation found in both Haval Banda Zaroka and Skhen hospitals surpassed the prescribed dose limit. There is an obvious health risk of radiation exposure for all the exposed population visiting radiography department of these hospitals. So, there is a necessity of adequate and appropriate radiation protection at these X-ray departments. The radiations measured at other hospitals were beyond the reference dose limit $1 \mathrm{mSv} \cdot \mathrm{yr}^{-1}$ and there were no risks for public.

It can be seen that from the results were obtained, dose values only in controlled and uncontrolled areas of both Bahdinan and Zakho hospitals are below prescribed dose limits due efficiency of protection as well as design of X-rays rooms in these hospitals.

Table 2. A comparison of the effective dose measured from maximum to minimum values for controlled area in the selected hospitals for all $\mathrm{kVp}$ and $\mathrm{mAs}$ ranges.

\begin{tabular}{|c|c|c|c|}
\hline \multirow{2}{*}{ Hospitals } & \multicolumn{3}{|c|}{ Effective dose $(\mathrm{mSv} / \mathrm{yr}) / \mathbf{k} \mathrm{V}_{\mathrm{p}}, \mathrm{mAs}$} \\
\hline & \multicolumn{3}{|c|}{$60,1.481,28105,45$} \\
\hline Haval Banda Zaroka & 0.26 & 2.28 & 12.98 \\
\hline Shekhan & 0.21 & 1.48 & 8.96 \\
\hline Khazer & 0.28 & 0.84 & 4.52 \\
\hline Golan/Akre & 0.22 & 0.40 & 3.21 \\
\hline Golan/Semel & 0.21 & ----- & 1.85 \\
\hline Bahdinan & 0.23 & 0.24 & 0.25 \\
\hline Zakho & 0.20 & 0.22 & 0.22 \\
\hline
\end{tabular}

Table 3. A comparison of the effective dose measured from maximum to minimum values for uncontrolled area in the selected hospitals for all $\mathrm{kVp}$ and $\mathrm{mAs}$ ranges.

\begin{tabular}{|c|c|c|c|}
\hline \multirow{2}{*}{ Hospitals } & \multicolumn{3}{|c|}{ Effective dose $(\mathrm{mSv} / \mathrm{yr}) / \mathrm{kV}_{\mathrm{p}}, \mathrm{mAs}$} \\
\hline & \multicolumn{3}{|c|}{$60,1.481,28105,45$} \\
\hline Khazer & 0.28 & 7.31 & 82.48 \\
\hline Haval Banda Zaroka & 0.25 & 1.80 & 12.93 \\
\hline Shekhan & 0.27 & 0.36 & 3.16 \\
\hline Golan/Akre & 0.22 & ---- & 0.56 \\
\hline Golan/Semel & 0.21 & 0.27 & 0.31 \\
\hline Bahdinan & 0.21 & 0.21 & 0.22 \\
\hline Zakho & 0.20 & 0.20 & 0.20 \\
\hline
\end{tabular}


A comparison can be seen in Table 4 between radiation measured only from background and radiation from background and X-ray together at staff and public areas in all hospitals. It can be noted that there was the large difference between radiation measured from background only and radiation from diagnostic X-rays with background together. Although there was less difference between them for some X-ray parameters and in some hospitals, the results are scare and immediate radiation protection actions must be initiated in order to keep exposure as low as reasonably achievable. It should be noted that dose from background radiation in Haval Banda Zaroka hospital is higher than other hospitals and this is in normal ranges of dose at this hospital due to high position (Amedi city) of the hospital from sea level.

Background radiation was measured for $\mu \mathrm{Sv}$ per hours then converted to $\mathrm{mSv}$ per years by multiplying measurements by 5 hours per day and six days per weeks and 52 weeks per year in order to make comparison between background and $\mathrm{X}$-rays radiation, time of working in the selected hospitals.

The large variation in doses observed in operators and public areas in the selected hospitals suggests that optimising procedure protocols and implementing general use of the most effective types of protective shields may reduce occupational radiation doses to operators as well as patients or visitors. It is considerable difficult to compare reported results of dosimetry because of significant differences in dosimetric methods used in each study. In addition, multiple factors affecting the actual doses received.

Table 4. A comparison of the effective dose measured from only background radiation and from diagnostic X-rays with background together in the selected hospitals.

\begin{tabular}{|c|c|c|c|}
\hline \multirow{2}{*}{ Hospitals } & \multicolumn{3}{|c|}{ Mean \pm SD $(\mathrm{mSv} / \mathrm{yr})$} \\
\hline & Controlled A. & Uncontrolled A. & Background radiation \\
\hline \multirow{3}{*}{ Bahdinan } & $0.23 \pm 0.01$ & $0.21 \pm 0.01$ & \multirow{3}{*}{$0.21 \pm 0.01$} \\
\hline & $0.24 \pm 0.02$ & $0.21 \pm 0.02$ & \\
\hline & $0.25 \pm 0.01$ & $0.22 \pm 0.02$ & \\
\hline \multirow{3}{*}{ Zakho } & $0.22 \pm 0.01$ & $0.21 \pm 0.01$ & \multirow{3}{*}{$0.22 \pm 0.01$} \\
\hline & $0.22 \pm 0.03$ & $0.22 \pm 0.01$ & \\
\hline & $0.23 \pm 0.02$ & $0.22 \pm 0.02$ & \\
\hline \multirow{3}{*}{ Golan/Semel } & $0.21 \pm 0.01$ & $0.22 \pm 0.03$ & \multirow{3}{*}{$0.21 \pm 0.01$} \\
\hline & ------------ & ------------ & \\
\hline & $1.85 \pm 0.03$ & $0.56 \pm 0.07$ & \\
\hline \multirow{3}{*}{ Haval Banda Zaroka } & $0.26 \pm 0.01$ & $0.25 \pm 0.01$ & \multirow{3}{*}{$0.26 \pm 0.03$} \\
\hline & $2.28 \pm 0.11$ & $1.80 \pm 0.08$ & \\
\hline & $12.98 \pm 0.16$ & $12.93 \pm 0.25$ & \\
\hline \multirow{3}{*}{ Golan/Akre } & $0.22 \pm 0.01$ & $0.21 \pm 0.03$ & \multirow{3}{*}{$0.21 \pm 0.02$} \\
\hline & $0.40 \pm 0.07$ & $0.27 \pm 0.03$ & \\
\hline & $3.21 \pm 0.81$ & $0.31 \pm 0.01$ & \\
\hline \multirow{3}{*}{ Khazer } & $0.28 \pm 0.04$ & $0.28 \pm 0.02$ & \multirow{3}{*}{$0.21 \pm 0.01$} \\
\hline & $0.84 \pm 0.02$ & $7.31 \pm 0.12$ & \\
\hline & $4.52 \pm 0.61$ & $82.48 \pm 0.73$ & \\
\hline \multirow{3}{*}{ Shekhan } & $0.21 \pm 0.02$ & $0.27 \pm 0.02$ & \multirow{3}{*}{$0.22 \pm 0.02$} \\
\hline & $1.48 \pm 0.23$ & $0.36 \pm 0.03$ & \\
\hline & $8.96 \pm 0.40$ & $3.16 \pm 0.18$ & \\
\hline
\end{tabular}




\section{Conclusion}

The aim of the present study was to determine whether effective dose from scattered and leaked photons at diagnostic X-rays departments exceeded dose limits that were considered by radiation protection agencies or not. Effective doses determined from the exposures generated by diagnostic X-rays machines were measured by using Gamma Scout Dosimeter. The measured doses were resulted from working of X-ray machines for ranges of $\mathrm{X}$-ray levels to identify radiation protection of X-rays rooms for different X-rays intensities. From the measurement results, it was seen that the most hospitals barriers (doors and walls) are not appropriate to the standards except 2 hospitals. Moreover, there are risks of high radiation for patients and people visiting X-rays departments of most hospitals as well as risks for clinical staff working at those X-rays departments. The highest effective doses were measured in uncontrolled area of Khazer hospital and the highest effective doses were measured in controlled area of Haval Banda Zaroka hospital. In addition, radiologists were not wearing any personal dosimeters, therefore, actual dose received by radiologists is not known. After data collections and analysis, it was found that radiation protection principles are neglected in most hospitals of Duhok governorate.

\section{References}

[1] Damilakis, J., Adams, J.E., Guglielmi, G. and Link, T.M. (2010) European Radiology, 20, 2707-2714. http://dx.doi.org/10.1007/s00330-010-1845-0

[2] Wahlstroem, B. (1997) Radiation, Health and Society. International Atomic Energy Agency (IAEA), Finland.

[3] ICRP (1991) Recommendations of the International Commission on Radiological Protection. ICRP Publication 60, Ann. ICRP 21 (1-3), Ottawa.

[4] ICRP (1993) Protection against Radon-222 at Home and at Work. ICRP Publication 65, Ann. ICRP 23 (2), Ottawa.

[5] ICRP (2004) Managing Patient Dose in Digital Radiology. ICRP Publication 93, Ann. ICRP 34 (1), Ottawa.

[6] IAEA (1997) Annual Report for 1997. IAEA Publications, New York.

[7] Simpkin, D.J. and Dixon, R.L. (1998) Health Physics, 74, 350-65. http://dx.doi.org/10.1097/00004032-199803000-00008

[8] National Council on Radiation Protection and Measurements (2004) Structural Shielding Design for Medical X-Ray Imaging Facilities. NCRP Publications, Bethesda.

[9] Radiological Protection Institute of Ireland (2009) The Design of Diagnostic Medical Facilities Where Ionizing Radiation Is Used. Radiological Protection Institute of Ireland, Dublin.

[10] Marshall, N.W. and Faulkner, K. (1992) The British Journal of Radiology, 65, 44-49. http://dx.doi.org/10.1259/0007-1285-65-769-44

[11] Alonso, J.A., Shaw, D.L., Maxwell, A., McGill, G.P. and Hart, G.C. (2001) The Journal of Bone and Joint Surgery, 83-B, 815-818. http://dx.doi.org/10.1302/0301-620X.83B6.11065

[12] Giri, K., Giri, D. and Murthy, V.K. (2007) Kathmandu University, Journal of Science, Engineering and Technology, 3, 31-34. http://dx.doi.org/10.3126/kuset.v3i2.2895

[13] Naji, A.T. and Jaafar, M.S. (2013) Advances Aterials Physics and Chemistry, 3, 191-193. http://dx.doi.org/10.4236/ampc.2013.33027 